\title{
Non-adenine based purines accelerate wound healing
}

\author{
Shucui Jiang • Caleb C. J. Zavitz • Jian Wang • \\ Amit Saraf • Robert Zielinski • James D. Ramsbottom • \\ Patrizia Ballerini • Iolanda D'Alimonte • \\ Silvia Romano • Gemma Fischione • Ugo Traversa • \\ Eva S. Werstiuk • Michel P. Rathbone
}

Received: 23 February 2006 / Revised: 22 May 2006 / Accepted: 29 May 2006 / Published online: 26 July 2006

(C) Springer Science + Business Media B.V. 2006

\begin{abstract}
Wound healing is a complex sequence of cellular and molecular processes that involves multiple cell types and biochemical mediators. Several growth factors have been identified that regulate tissue repair, including the neurotrophin nerve growth factor (NGF). As non-adenine based purines (NABPs) are known to promote cell proliferation and the release of growth factors, we investigated whether NABPs had an effect on wound healing. Full-thickness, excisional wound healing in healthy BALB/c mice was significantly accelerated by daily topical application of NABPs such as guanosine $(50 \%$ closure by days 2.5 2.8). Co-treatment of wounds with guanosine plus anti-NGF reversed the guanosine-promoted acceleration of wound healing, indicating that this effect of guanosine is mediated, at least in part, by NGF. Selective inhibitors of the NGF-
\end{abstract}

\footnotetext{
S. Jiang $(\bowtie)$

Department of Surgery, McMaster University

Health Sciences Centre, 4N71B, 1200 Main Street West,

Hamilton, Ontario L8N 3Z5, Canada

e-mail: jiangs@mcmaster.ca

C. C. J. Zavitz $\cdot$ J. Wang $\cdot$ A. Saraf $\cdot$ R. Zielinski $\cdot$

J. D. Ramsbottom $\cdot$ E. S. Werstiuk $\cdot$ M. P. Rathbone

Department of Medicine, McMaster University

Health Sciences Centre, 4N71B, 1200 Main Street West,

Hamilton, Ontario, Canada

P. Ballerini $\cdot$ I. D'Alimonte $\cdot \mathrm{S}$. Romano $\cdot$ G. Fischione $•$

M. P. Rathbone

Department of Biomedical Sciences, Universita Degli Studi

"G. D’Annunzio", University Of Chieti,

Nuovo Polo Didattico, Chieti, Italy

U. Traversa

Department of Biomedical Sciences, Pharmacology,

University of Trieste, Trieste, Italy
}

inducible serine/threonine protein kinase (protein kinase $\mathrm{N}$ ), such as 6-methylmercaptopurine riboside abolished the acceleration of wound healing caused by guanosine, confirming that activation of this enzyme is required for this effect of guanosine. Treatment of genetically diabetic BKS. $\mathrm{Cg}-\mathrm{m}+/+$ lepr $\mathrm{db}$ mice, which display impaired wound healing, with guanosine led to accelerated healing of skin wounds $(25 \%$ closure by days $2.8-3.0)$. These results provide further confirmation that the NABP-mediated acceleration of cutaneous wound healing is mediated via an NGF-dependent mechanism. Thus, NABPs may offer an alternative and viable approach for the treatment of wounds in a clinical setting.

Key words $\mathrm{BALB} / \mathrm{c}$ mice . genetically diabetic mice guanosine - inosine - NGF - non-adenine based purines . protein kinase $\mathrm{N} \cdot$ wound healing

\section{Introduction}

Healing of skin wounds is an essential process in the response of tissues to injury. Although most wounds heal rapidly, impaired or delayed tissue repair represents a major clinical challenge. Most failed or delayed healing is associated with some form of host impairment, such as diabetes, infection, immunosuppression or vascular insufficiency $[1,2]$. The biological processes in wound healing occur in sequential phases, which include coagulation, inflammation, tissue formation and tissue remodelling [3]. Injury to the skin is often associated with the extravasation of blood from injured vessels. Platelet aggregation and blood coagulation at the injury site initiate the healing process, and the subsequent inflammatory stage starts with the migration of polymorphonuclear neutrophils, followed 
by macrophages as the immune system is activated. The regulated attraction of leukocytes is essential to ensure a well-ordered inflammatory process that initiates tissue repair. As repair and inflammation progress, new tissue is formed, the extracellular matrix is rebuilt, and fibroplasia and angiogenesis occur [4]. These steps progress in a coordinated manner and require the presence of various cytokines, growth factors and other bioactive molecules $[3$, 5-7]. Interruption at any point in this highly regulated process results in impaired wound healing.

Previous studies have demonstrated that growth factors synthesized by several cells of the healing wound promote tissue repair [3, 5, 7], and topical application of growth factors such as platelet-derived growth factor, or fibroblast growth factor, or epidermal growth factor accelerate wound healing $[3,5,7,8]$. Nerve growth factor (NGF) is considered to be particularly important in promoting tissue repair; it regulates the survival and differentiation of neurons $[9,10]$ and is important in wound healing, since topical application of this neurotrophin has been shown to improve the rate of wound healing in healthy mice [11-13] as well as in genetically diabetic mice $[12,14]$. In diabetic animals the NGF content of the skin is reduced [12], and this may contribute to the delayed repair of diabetic wounds.

The first evidence that a small molecule may also regulate the process of wound healing was shown by the adenosine $\mathrm{A}_{2 \mathrm{~A}}$ receptor agonist, CGS-21680 (4-[\{N-ethyl5 -carbamoyladenos-2-yl $\}$ aminoethyl]phenylpropionic acid [15]. This purine analogue activates the Gs-protein linked adenosine $\mathrm{A}_{2 \mathrm{~A}}$ receptor, and, by increasing intracellular cAMP [16], it accelerated wound healing in healthy mice as well as in diabetic mice. More recently, these findings in healthy mice were confirmed by the use of another highly selective adenosine $\mathrm{A}_{2 \mathrm{~A}}$ receptor agonist, MRE0094 (2-[2-(4-chlorophenyl)ethoxy]adenosine [17]. It is interesting to note that another adenosine analogue, cyclopentyladenosine (CPA), has also been reported to accelerate wound healing [18]. This adenosine derivative is a highly selective agonist at the adenosine $A_{1}$ receptors, which inhibit adenylyl cyclase synthesis and, thus, decrease intracellular cAMP concentrations [16]. Extracellular ATP has also been suggested as a potential mitogenic modulator of cells involved in wound repair [19, 20], and, recently, Greig and colleagues provided comprehensive evidence in support of an NGF-dependent role of purinergic receptors and thus purinergic signalling $[21,22]$.

Besides adenosine analogues, non-adenine based purines (NABPs), such as guanosine and inosine, also have potent effects on growth and differentiation of a wide range of cells [23-24]. These purines do not interact with adenosine receptors, and their modes of action appear to be distinct from those of the adenine-based compounds [23, 25, 26].
Non-adenine based purines exert a number of trophic effects on cell proliferation and cell differentiation in a variety of cell types [23-25, 27-30], including proliferation of capillary endothelial cells (processes that are important in wound healing). Some of these effects of guanosine are mediated by activation of its high-affinity putative receptor site expressed in rat brain membranes [26] and in cultured rat astrocytes [31]. Other effects may be mediated by the ability of guanosine to stimulate the release of trophic factors from cells, including NGF [23, 25, 32]. As reviewed above, NGF plays an important role in promoting wound healing [11-14, 33, 34].

These findings led us to the hypothesis that non-adenine based purines may enhance wound healing and do so through mechanisms distinct from those mediated by adenosine-based purines. The purpose of this study was to determine whether non-adenine based purines had any effect on healing of excisional dermal wounds in normal, healthy mice. Since NGF production and wound healing are impaired in diabetes [12, 14, 33], we also tested the effect of non-adenine based purines on wound healing in genetically diabetic mice.

\section{Materials and methods}

Study design

Normal, healthy, female mice 6-7 weeks old (BALB/c, Charles River, Wilmington, Mass., USA; average blood glucose level $6.0 \mathrm{mM}$ ) and female genetically diabetic mice (BKS.Cg-m+/+lepr db, Jackson Laboratories, Bar Harbor, Me., USA; average blood glucose level: $23.8 \mathrm{mM}$ ) were obtained. Mice were housed in level B conditions (specific pathogen free) at the Central Animal Facility (CAF) of McMaster University on a $12 \mathrm{~h}$ light/dark cycle. On arrival, animals were housed in groups and were acclimatized to their surroundings for 6 days. All mice were given free access to standard rodent chow and water. Animal care was in accordance with the guidelines of the Canadian Council on Animal Care and the McMaster University Animal Research Ethics Board.

\section{Excisional wound formation}

Mice were anaesthetized with isoflurane (3-5\%), $\mathrm{O}_{2}$ $(1.5 \mathrm{l} / \mathrm{min})$ in a level B surgical suite. Two sterile, fullthickness, excisional wounds $(1.0 \mathrm{~cm}$ in diameter $)$ were made on either side of the dorsum of mice, using a template and surgical scissors [15]. Wounds were separated by a minimum of $1.0 \mathrm{~cm}$ of unwounded skin. Mice were housed individually after the wounds were made to prevent licking and scratching by cage mates. 


\section{Compounds tested}

Guanosine, guanine, guanosine triphosphate, 8-bromoguanosine, 7-methyl-guanosine, hypoxanthine, inosine, 6-thioguanine (6-TG), 6-methyl mercaptopurine riboside (6-MMPR), 6-thioguanosine and all other agents used in the study were purchased from Sigma (St. Louis, Mo., USA) unless otherwise stated. All purine analogues were dissolved in $1 \mathrm{M} \mathrm{NaOH}$ and made to the required concentration by the addition of either distilled $\mathrm{H}_{2} \mathrm{O}$ or phosphate-buffered saline (PBS); the $\mathrm{pH}$ of the solutions was adjusted to $\mathrm{pH} 7.4$ with $1 \mathrm{M} \mathrm{HCl}$. Before use, drug solutions were filtered through a $0.2 \mu \mathrm{m}$ HT Tuffrym membrane (Acrodize), and warmed to $37{ }^{\circ} \mathrm{C}$. NGF and neutralizing antibodies to NGF $(25 \mu \mathrm{g} / \mathrm{ml}$; anti-NGF) were a generous gift from Dr. M.D. Coughlin, Department of Medicine, McMaster University.

\section{Treatment of wounds}

In each experiment 4-7 mice were randomly assigned to the different treatment groups. Most experiments were repeated at least three times. Investigators who measured the size of the wound were unaware of the treatment groups. Wounds were treated by topical application of either $20 \mu \mathrm{l} 1.5 \% \mathrm{w} / \mathrm{v}$ carboxymethylcellulose (CMC) in PBS (control) or $20 \mu \mathrm{l}$ of one of the non- adenine based purine analogues in CMC $(1.5 \% \mathrm{w} / \mathrm{v})$ at the same time each day for 7-8 consecutive days following wounding. We applied drug solutions topically to each wound by pipetting the solution onto the wound surface and spread them uniformly across the entire wound with the edge of the pipette tip.

\section{Determination of wound area}

To facilitate accurate visualization of the wound margins and to facilitate access of the test agents to the wound, scabs were gently removed on days 4, 5, 6 and 7 after wounding [18]. At the time the wounds were made, the skin was easily stretched, so that the wound areas varied considerably during measurement, making an accurate assessment of wound size very difficult. To avoid the potentially confounding effects of this variability, wound outlines were traced onto thin transparent plastic sheets on the day after the wounds were made, and this was defined as day zero of the treatment period. Daily measurements were then made in duplicate for 7-8 days. Because the absolute rates of wound healing varied between groups of mice, matched controls were performed for every experimental group.
Quantification of wound area

Transparencies containing the tracings of the wounds were scanned into an Apple iMac computer using an Agfa scanner, and their segmentation was analysed and binarized using IPLab software (version 3.5; Scanalytics, Inc., Fairfax, Va., USA). For each animal the area of the wound was determined every day for a 7-8 day period, and this was compared with the area of the wound on day zero of the treatment period. The percentage of wound closure (i.e., healing) was calculated for each experimental animal in every treatment group by comparison of the mean values of wound size determined at each time point to the day zero values. The average wound closure within a group for each day was plotted on a graph and was compared with that of other treatment groups.

\section{Histology}

On days 1, 2, 3, 4 and 5 after wounding, mice were euthanized by $\mathrm{CO}_{2}$ narcosis. Tissue samples, including the entire wound area and underlying muscles of the body flank, were dissected and fixed for 1 week in phosphatebuffered $10 \%$ formalin. Each tissue sample was carefully trimmed with a fresh razor blade to eliminate any unwounded tissue. Tissues were dehydrated in increasing concentrations of alcohol and xylene and embedded in paraffin, and $0.5 \mathrm{~mm}$ thick sections were cut and mounted on glass slides, stained with haematoxylin and eosin and covered with a coverslip. All sections were examined under a light microscope by an investigator who was unaware of whether the sample was from a treated or a control group.

\section{Statistical analysis}

Wound areas, calculated as described above, were entered into Microsoft Excel 2000. For each wound, differences between the area on the first day and each subsequent day were expressed as a percentage of the area for each animal on day zero. Owing to the degree of variability observed between groups of mice in the absolute rates of wound healing, each experiment included its own vehicle control. Results are presented as a percentage of wound area closed over time or as the time required for each wound to reach $50 \%$ closure.

Percentage-of-wound-closure data were also transformed into arcsin SQRT (percent) values, and the following statistical analyses were performed. Data were analysed by linear regression analysis, and the slopes and the intercepts in the control group were compared with those of the various treatment groups. Results from the effect of the various treatments over time were analysed by a two-way 
analysis of variance (ANOVA), followed by Bonferroni's test. $P<0.05$ was considered statistically significant.

\section{Results}

Spontaneous healing of excisional dermal wounds in healthy adult mice

We observed that, in healthy BALB/c mice, $1 \mathrm{~cm}$ diameter excisional dermal wounds healed spontaneously, as has been reported by others [15]. Therefore, in these experiments, we studied the effects of treatments with non-adenine based purines on the acceleration of wound closure.

Guanosine accelerates the rate of wound healing in healthy adult mice

Excisional wounds of $\mathrm{BALB} / \mathrm{c}$ mice were treated daily for 6-7 days with guanosine in $1.5 \% \mathrm{CMC}$ in concentrations ranging from $50 \mu \mathrm{M}$ to $1,000 \mu \mathrm{M}$. Another group of mice was treated with $1.5 \% \mathrm{CMC}$ only (vehicle control) for the same time, and the rate of wound healing was compared in the two groups of mice. Guanosine $(250 \mu \mathrm{M})$, administered topically once daily, enhanced the rate of wound healing compared to that of vehicle-treated controls $(P<0.001, n=$ 8 , Figure 1). Other concentrations of guanosine $(500 \mu \mathrm{M}-$ $1,000 \mu \mathrm{M})$ had no significant effect on wound closure. Twice-daily treatments with guanosine $(250 \mu \mathrm{M})$ accelerated wound closure to an even greater extent than a oncedaily application of guanosine. The effect of this treatment was highly significant when compared with that of vehicletreated controls $(P<0.001, n=10$, data not shown).

Effect of guanosine on wound morphology

In the first 2 days after injury histological examination of wounds in control mice showed a necrotic crust, averaging $100-400 \mu \mathrm{m}$ in thickness, overlying a diffuse infiltration of inflammatory cells. Beneath the dense layer of inflammatory cells the tissue was oedematous and contained tissue exudates, indicating active inflammation. In contrast, in guanosine-treated mice at 2 days, the necrotic crust was much thinner, and the inflammatory response was much less. There was very little oedema, and tissue ingrowth beneath the layer of inflammatory cells was noticeable. Many of the cells appeared to be spindle shaped, consistent with the appearance of healthy fibroblasts. The matrix tissue appeared to be more organized and compact in the guanosine-treated wounds than in controls (Figure 2). Histological examination of wounds treated with guanosine revealed several marked differences from those treated with vehicle alone, and may offer some clues to potential cellular

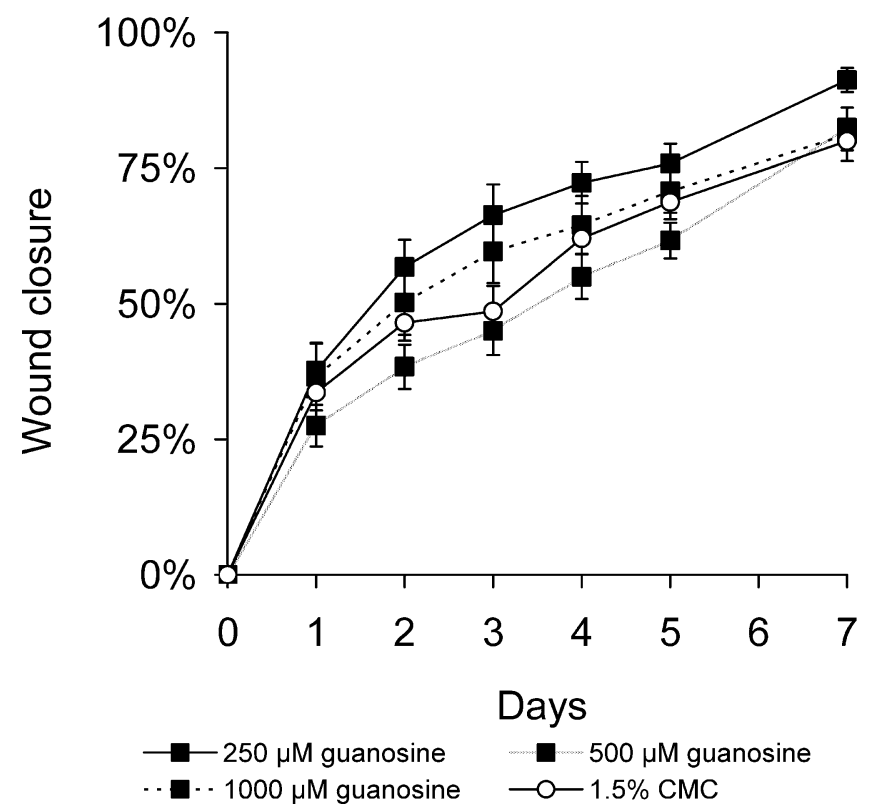

Figure 1 Guanosine accelerates the rate of wound healing in healthy adult mice. Full-thickness, excisional, dermal wounds of healthy, young, adult BALB/c mice were treated with guanosine $(250 \mu \mathrm{M}-$ $1,000 \mu \mathrm{M})$ or with $1.5 \% \mathrm{CMC}$, administered topically, once daily. Areas of wounds were measured daily and quantified as described in the Methods and materials section. Daily administration of guanosine $(250 \mu \mathrm{M})$ increased significantly the rate of wound healing compared with that in vehicle-treated controls (mean \pm SEM, $n=8 ; P<0.001$ ). Other concentrations of guanosine had no significant effect on wound closure

targets. Vehicle-treated wounds had substantially more accumulation of fibrinous exudate under the superficial crust, as well as a greater leukocytic infiltration within the underlying muscle than did wounds that had been treated with guanosine. The large accumulation of fibrinous exudate is believed to be due to severe vascular damage to the deep subcutaneous blood vessels at the time of skin injury, with extravasation of plasma proteins, including fibrinogen, within the first 2 days following surgery [4]. Infiltration of the fibrinous exudate by neutrophils is considered an acute inflammatory response of the tissues to injury, driven by a constant demand for neutrophils during the formation and maintenance of the superficial crust $[4,6]$. The less pronounced accumulation of fibrinous exudate in the guanosine-treated wounds at 2 days after wounding coincided with reduced infiltration of the tissues underlying the superficial crust and was temporally related to the acceleration of wound closure.

Guanosine-induced acceleration of wound healing is mediated by NGF

Cutaneous wound healing is promoted by several different growth factors [8], including NGF [12, 13]. Guanosine [32] and the hypoxanthine derivative, AIT-082 [35] have been 


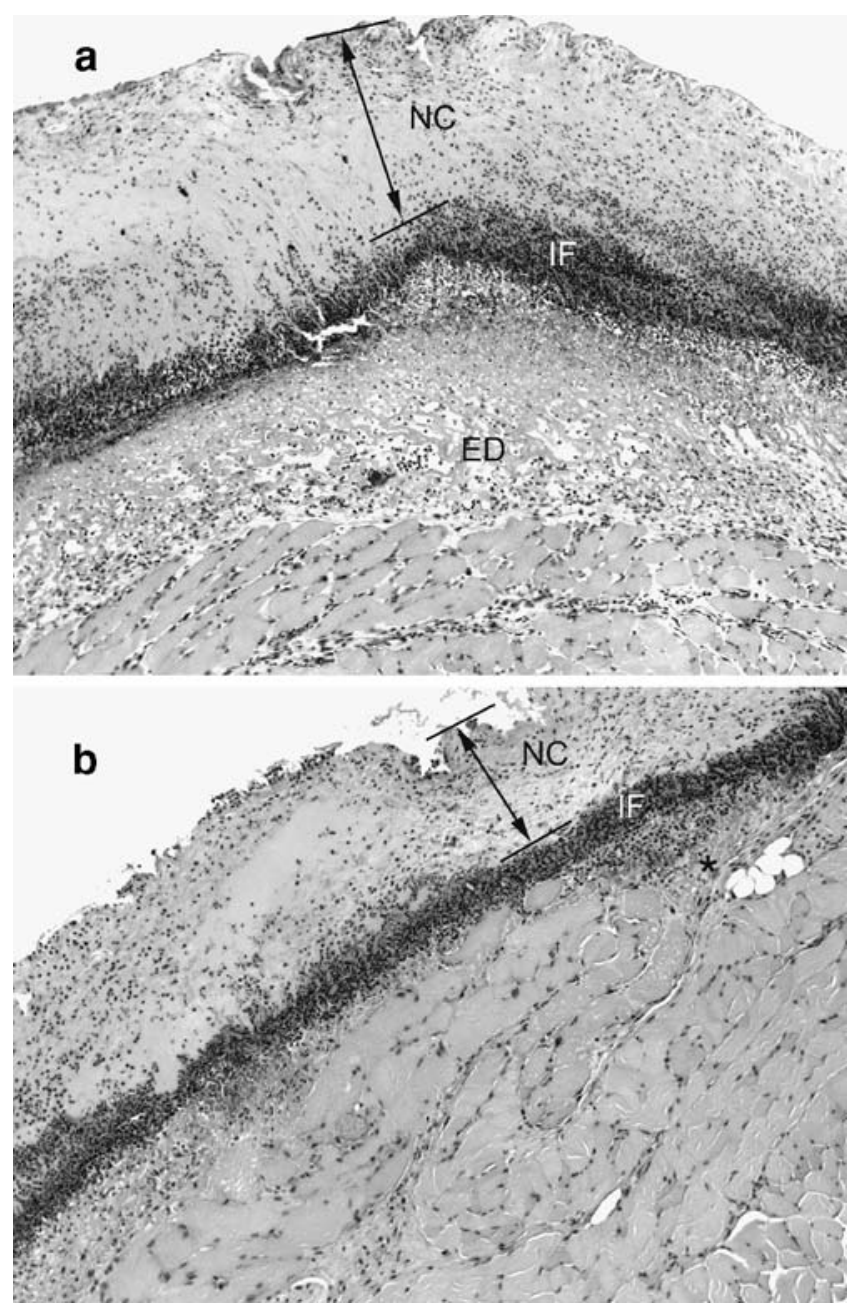

Figure 2 Effect of guanosine on wound inflammation. Sections of skin wounds stained with haematoxylin and eosin 2 days after injury. (a) Wound from mouse treated with vehicle control solution showed a necrotic crust (NC, and arrow between lines) overlying a diffuse infiltration of inflammatory cells $(I F)$. Beneath the dense layer of inflammatory cells the tissue was oedematous and contained tissue exudates $(E D)$, indicating active inflammation. (b) In contrast, in guanosine-treated mice at 2 days, the necrotic crust ( $N C$, and arrow between lines) was much thinner, and the inflammatory response was much less. There was very little oedema, and tissue ingrowth beneath the layer of inflammatory cells was noticeable. Many of the cells appeared to be spindle shaped, consistent with the appearance of healthy fibroblasts (star). The matrix tissue appeared to be more organized and compact in the guanosine-treated wounds than in controls

shown to stimulate the synthesis and release of NGF from cultured astrocytes. We therefore questioned whether the acceleration in wound healing observed in guanosinetreated mice was mediated via NGF. As reported by others $[12,13]$, we also found that daily application of $100 \mu \mathrm{g} / \mathrm{ml}$ of the $2.5 \mathrm{~S}$ form of NGF to the wounds of the mice increased the rate of wound healing compared to that of CMC-treated controls (data not shown). Treatment of wounds with guanosine $(250 \mu \mathrm{M})$ accelerated wound healing, as previously described $(P<0.05)$. Time required for $50 \%$ closure in guanosine-treated wounds was 1.1 days (mean $\pm \mathrm{SEM}, n=10$ ) compared with 1.7 days in controls (mean \pm SEM, $n=10$ ) (Figure 3). Daily treatment of wounds with the neutralizing antibody to NGF $(25 \mu \mathrm{g} / \mathrm{ml})$ alone slowed the rate of wound healing (Figure 3). Time required for $50 \%$ closure in the antiNGF-treated mice was 2.5 days. Daily co-treatment of wounds with guanosine $(250 \mu \mathrm{M})$ and the neutralizing antibody to NGF $(25 \mu \mathrm{g} / \mathrm{ml})$ abolished the guanosineinduced acceleration of wound healing, so time for $50 \%$ wound healing was 1.7 days (mean $\pm \mathrm{SEM}, n=10$; Figure 3). These results indicate that, at least in part, NGF mediates the acceleration of wound healing by guanosine.

Guanosine-induced acceleration of wound healing is inhibited by 6 -MMPR

In PC12 cells and peripheral neurons NGF has been shown to promote neurite outgrowth by activating the NGF-inducible protein kinase $\mathrm{N}$, a partially characterized serine-threonine kinase [36-38]. Benowitz et al. (in 1998) [39] found that axon outgrowth in fish retinal ganglion cells

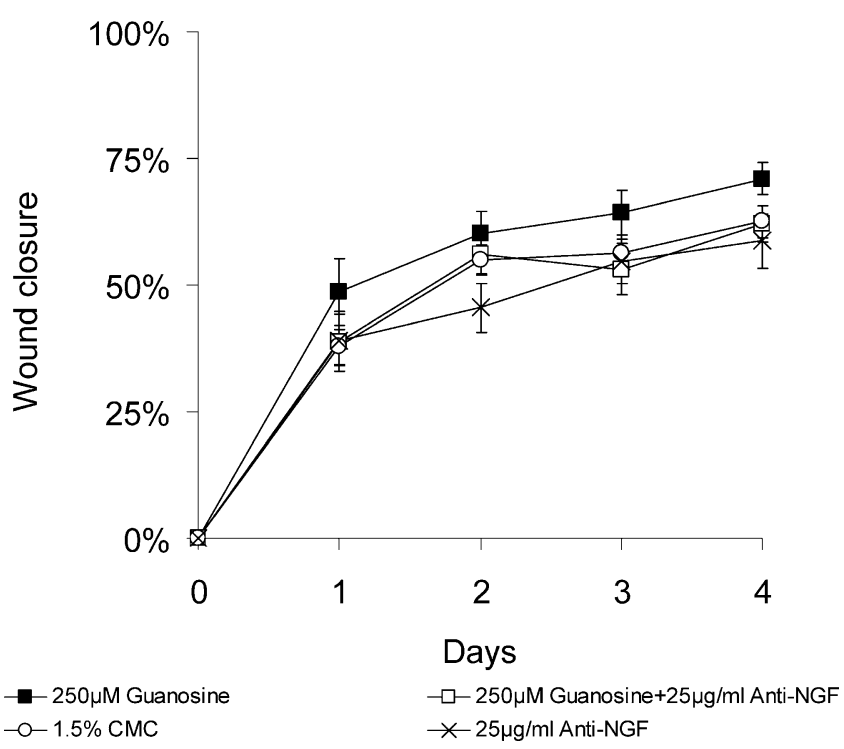

Figure 3 Guanosine-induced acceleration of wound healing is mediated by NGF. Full-thickness, excisional, dermal wounds of healthy, young, adult BALB/c mice were treated with guanosine $(250 \mu \mathrm{M})$, or anti-NGF $(25 \mu \mathrm{g} / \mathrm{ml})$, or with guanosine $(250 \mu \mathrm{M})$ plus anti-NGF $(25 \mu \mathrm{g} / \mathrm{ml})$, or with $1.5 \% \mathrm{CMC}$, administered topically, once daily. Areas of wounds were measured daily and quantified as described in the Methods and materials section. Daily administration of guanosine $(250 \mu \mathrm{M})$ increased significantly the rate of wound healing compared with that of vehicle-treated controls. Time required for $50 \%$ closure in guanosine treated wounds was 1.1 days (mean \pm SEM, $n=10$ ), compared with 1.7 days in controls (mean $\pm \mathrm{SEM}, n=10$ ). Daily treatment of wounds with anti NGF slowed the rate of healing to 2.5 days (mean \pm SEM, $n=10$ ). Cotreatment with guanosine plus anti-NGF prolonged the time required for $50 \%$ wounds closure to 1.7 days (mean \pm SEM, $n=10$ ) 
is also mediated by this enzyme. NGF-inducible protein kinase $\mathrm{N}$ is inhibited by the purine analogue, 6-TG (apparent $\mathrm{Ki}=6 \mu \mathrm{M}$ [37]), and even more potently by 6-MMPR, (apparent $\mathrm{Ki}=5 \mathrm{nM} \mathrm{[40]).} \mathrm{We} \mathrm{therefore}$ examined whether 6-MMPR had any effect on guanosineinduced acceleration of wound healing. Daily application of 6-MMPR $(100 \mu \mathrm{M})$ alone had no significant effect on wound healing (Figure 4). Treatment of wounds with guanosine $(250 \mu \mathrm{M})$ again increased the rate of wound healing on days 1 through $5(P<0.02)$ (Figure 4). Time required for $50 \%$ wound closure in guanosine-treated mice was 2.0 days (mean \pm SEM, $n=5$ ) compared with 4.1 days in controls (mean $\pm \mathrm{SEM}, n=5$; Figure 4). Co-application of guanosine $(250 \mu \mathrm{M})$ plus 6-MMPR $(100 \mu \mathrm{M})$ abolished the acceleration of wound healing caused by guanosine treatment. Time required for $50 \%$ wound closure in guanosine plus 6-MMPR treated mice was 4.0 days (mean \pm SEM, $n=5$; Figure 4). Similar effects were also seen when wounds were co-treated with guanosine $(250 \mu \mathrm{M})$ plus $6-\mathrm{TG}(1000 \mu \mathrm{M}$, data not shown). These findings indicate that activation of the NGF-inducible

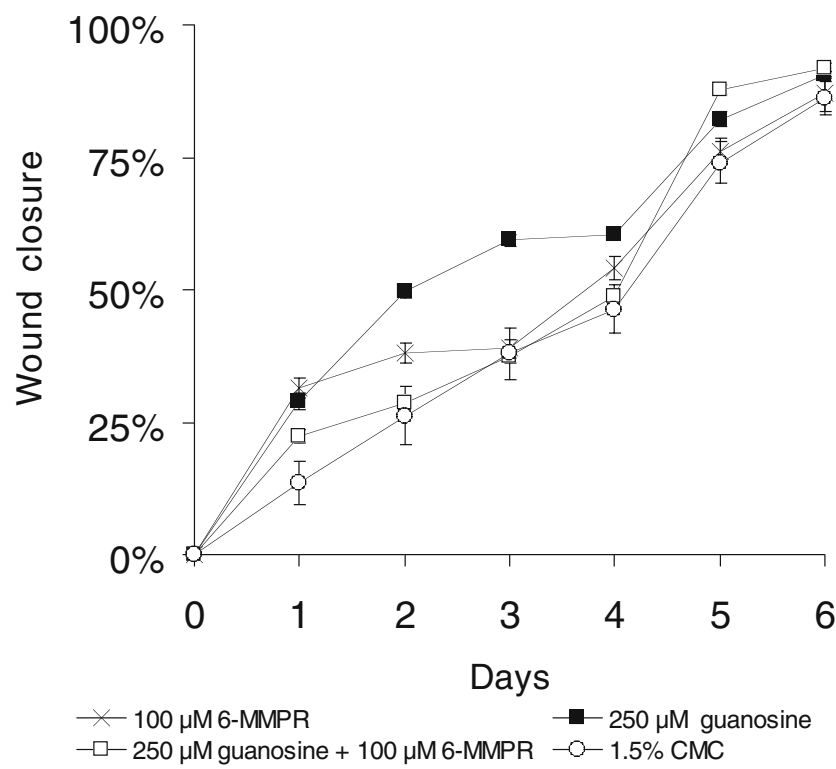

Figure 4 Guanosine-induced acceleration of wound healing is inhibited by 6-MMPR. Full-thickness, excisional, dermal wounds of healthy, young, adult BALB/c mice were treated with guanosine $(250 \mu \mathrm{M})$, or with 6 -MMPR $(100 \mu \mathrm{M})$ or with guanosine $(250 \mu \mathrm{M})$ plus 6-MMPR $(100 \mu \mathrm{M})$, or with $1.5 \% \mathrm{CMC}$, administered topically, once daily. Areas of wounds were measured daily and quantified as described in the Methods and materials section. Daily administration of guanosine $(250 \mu \mathrm{M})$ increased significantly the rate of wound healing compared with that of vehicle-treated controls. Time required for $50 \%$ closure in guanosine-treated mice was 2.0 days (mean \pm SEM, $n=5$ ) compared with 4.1 days in controls (mean \pm SEM, $n=5$ ). Daily application of 6-MMPR alone to the wounds had no significant effect on healing time. Co-treatment of wounds with guanosine $(250 \mu \mathrm{M})$ plus 6-MMPR $(100 \mu \mathrm{M})$ abolished the guanosine-induced acceleration of wound healing. Time required for $50 \%$ wound closure in guanosine $(250 \mu \mathrm{M})$ plus 6-MMPR $(100 \mu \mathrm{M})$ treated mice was 4.0 days (mean $\pm \mathrm{SEM}, n=5$ ) protein kinase $\mathrm{N}$ may, at least in part, contribute to the guanosine-promoted acceleration of wound healing.

Guanosine accelerates the rate of wound healing in genetically diabetic mice

In various animal models of diabetes NGF content of the peripheral nerves is reduced, and this may contribute to the impaired regeneration of the damaged tissue [41]. Recent reports have also demonstrated that the NGF content in wounds of diabetic mice is significantly reduced [33], and that treatment of wounds of these mice with NGF accelerates wound healing $[12,14]$. Since our data in normal mice implied that non-adenine based purines accelerated wound healing via an NGF-dependent mechanism, we therefore examined whether application of guanosine to the wounds of genetically diabetic mice, BKS.Cg-m $+/+$ lepr $\mathrm{db}$, had any effect on the rate of wound healing. As reported by others [12], wounds of the diabetic mice took longer to heal than those of normal mice treated with $1.5 \%$ CMC (compare Figure 5 with other figures). Topical application of guanosine $(250 \mu \mathrm{M})$ once daily for 14 days enhanced the rate of wound healing in genetically diabetic mice compared with that of vehicle-treated diabetic mice in the first few days after injury (Figure 5). In preliminary experiments, treatments were conducted for up to 14 days, but, subsequently, it was determined that differences between treated and control groups became negligible beyond day 8 , so experiments were shortened to reflect this fact.

Time required for $25 \%$ wound closure in guanosinetreated diabetic mice was 2.8-3 days (mean \pm SEM, $n=18$; Figure 5) compared with 4 days in diabetic mice treated with $1.5 \%$ CMC (mean $\pm \mathrm{SEM}, n=20$; Figure 5). This improvement was detected as early as 1 day after treatment, was maximal over the first 2 days $(P<0.02)$ and was sustained for up to 4 days (Figure 5).

Effect of non-adenine based purines on wound healing in healthy adult mice

We also examined the effect of a number of other naturally occurring purine derivatives, such as guanine, GTP, inosine, hypoxanthine, and the synthetic guanosine analogues 8-bromo-guanosine and 7-methylguanosine, on the rate of wound healing in healthy adult mice (Table 1). Treatment of mice $(n=5-7)$ with each purine analogue was performed as a separate experiment, with its own matched vehicle control $(1.5 \% \mathrm{CMC}, n=5-7)$. Daily application of guanine $(250-1,000 \mu \mathrm{M})$ to the wounds of healthy mice also accelerated the rate of wound healing compared with that of vehicle control. Time required for $50 \%$ wound closure was 2.2 days in guanine $(250 \mu \mathrm{M})$-treated mice versus 3.8 days 


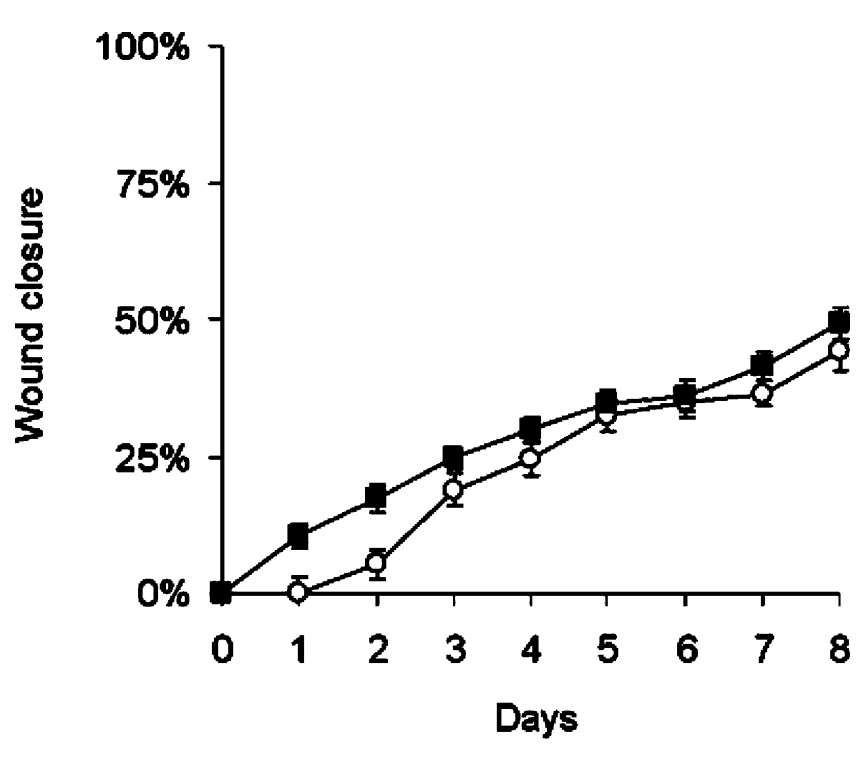

$-0-1.5 \%$ CMC -2 -250 MM Guanosine

Figure 5 Guanosine accelerates the rate of wound healing in genetically diabetic mice. Full-thickness, excisional, dermal wounds of genetically diabetic mice (BKS.Cg-m+/lepr $\mathrm{db}$ ) were treated with guanosine $(250 \mu \mathrm{M})$ or with $1.5 \% \mathrm{CMC}$ topically, daily. Areas of wounds were measured daily and quantified as described in the Methods and materials section. Daily treatment of wounds with guanosine $(250 \mu \mathrm{M})$ accelerated the rate of healing compared with that in vehicle controls. Time required for $25 \%$ wound closure in the guanosine $(250 \mu \mathrm{M})$-treated diabetic mice was 3.0 days (mean $\pm \mathrm{SEM}, n=18$ ) compared with 4.2 days in mice treated with vehicle only (mean \pm SEM, $n=20$ )

in the control animals that received the CMC alone. However, treatment of wounds with GTP, using a similar concentration range, had only a slight effect. Daily application of inosine $(250-1,000 \mu \mathrm{M})$ to the wounds of healthy young mice accelerated the rate of wound healing compared with that of mice treated with $\mathrm{CMC}$ alone. Time required for $50 \%$ wound closure was 1.2 days in inosine $(250 \mu \mathrm{M})$-treated mice versus 2.8 days in the control animals. Inosine-induced enhancement of wound healing was reduced by co-application of inosine $(250 \mu \mathrm{M})$ plus 6-MMPR $(100 \mu \mathrm{M})$ or inosine $(250 \mu \mathrm{M})$ plus 6-TG $(1,000 \mu \mathrm{M})$ (data not shown). These findings demonstrate that the enhancement of wound closure by inosine is also mediated by activation of the partially characterized NGFinducible serine-threonine kinase, protein kinase N. Treatment of wounds with hypoxanthine $(250 \mu \mathrm{M})$ also accelerated the wound healing time. Time required for $50 \%$ wound closure was 2.4 days in hypoxanthine $(250 \mu \mathrm{M})$-treated mice versus 3.25 days in the control animals that received the $\mathrm{CMC}$ alone.

Wounds of healthy mice treated daily with the synthetic guanosine derivative, 7-methylguanosine, had a reduced healing time compared with mice treated with $\mathrm{CMC}$ alone. Time required for $50 \%$ wound closure was 2.7 days in 7 -methylguanosine $(250 \mu \mathrm{M})$-treated mice versus 4.0 days in the control animals that received the CMC alone. In contrast, daily application of 8-bromo-guanosine $(250 \mu \mathrm{M})$ to wounds had only a slight accelerating effect on wound healing. Time required for $50 \%$ wound closure was 3.3 days in 8 -bromoguanosine $(250 \mu \mathrm{M})$-treated mice versus 3.8 days in the control animals that received the $\mathrm{CMC}$ alone.

\section{Discussion}

The present study is the first to report the effects of the nonadenine based purine nucleosides, guanosine and inosine, on the rate of wound healing in both normal and genetically diabetic mice. The results demonstrate that topical application of guanosine or inosine significantly increased the

Table 1 Effect of non-adenine based purines on wound healing in healthy adult mice. Full-thickness, excisional, dermal wounds of healthy, young, adult BALB/c mice $(n=5-7)$ were treated with selected naturally occurring purines: guanosine, guanine, GTP, inosine, hypoxanthine or the synthetic guanosine derivatives 8-bromoguanosine or 7-methylguanosine, all at ( $250 \mu \mathrm{M})$, administered topically, once daily for 7-8 days. For each treatment group matched controls $(n=5-7)$ were treated with $1.5 \% \mathrm{CMC}$. Areas of wounds were measured daily and quantified as described in the Methods and materials section. The rate of wound healing was accelerated by guanosine, guanine, inosine, hypoxanthine, and 7methylguanosine. GTP and 7-methylguanosine had no effect on wound closure. Results are presented as time required for $50 \%$ wound closure. + Accelerates wound healing, $N E$ no effect.

\begin{tabular}{llll}
\hline Non-adenine based purine & Treatments $^{\mathrm{a}}$ & Control $^{\mathrm{b}}$ & Effects $^{\text {(n) }}$ \\
\hline Guanosine & $2.5-2.8$ & 4.00 & + \\
Guanine & 2.20 & 3.80 & + \\
GTP & 3.35 & 3.10 & $\mathrm{NE}$ \\
Inosine & 1.20 & 2.80 & + \\
Hypoxanthine & 2.40 & 3.25 & $\mathrm{NE}$ \\
8-Bromoguanosine & 3.30 & 3.80 & + \\
7-Methylguanosine & 2.70 & 4.00 & + \\
\hline
\end{tabular}

${ }^{\mathrm{a}}$ All non-adenine based purines were tested at $250 \mu \mathrm{M}$ concentration.

${ }^{\mathrm{b}}$ Control mice were treated with $1.5 \% \mathrm{CMC}$. 
healing rate of wounds in young, healthy mice, as well as in genetically diabetic mice.

Previous studies have focused on the effect of adenosine analogues in wound healing. Cyclopentyladenosine, a selective agonist of the $A_{1}$ adenosine receptor, has been reported to stimulate the proliferation of keratinocytes, fibroblasts and endothelial cells, thereby promoting wound healing [18]. CGS-21680, acting via $\mathrm{A}_{2 \mathrm{~A}}$ adenosine receptors, has also been reported to enhance healing through promoting fibroblast and endothelial cell migration to the wound site [15]. Moreover, various P2Y and P2X purinergic receptors responsive to ATP and to UTP have been implicated in various aspects of wound healing [20], including P2X5, P2X7, P2Y1 and P2Y2 [21, 22].

Although both adenosine and purinergic P2 receptors have been found to have a role in wound healing, hitherto, non-adenine based purines have not been known to play a role. However, our data demonstrate that guanosine and inosine may also accelerate wound healing. Each active non-adenine based purine showed an inverted U-shaped concentration-dependence curve. This is a common pharmacological phenomenon. In previous studies we have shown that several non-adenine-based purines that promote cell proliferation in vitro at lower concentrations also inhibit cell proliferation at higher concentrations [24, 25]. Therefore it is not unexpected that there should be a similar concentration-dependence curve in vivo.

The mechanism by which non-adenine based purines accelerate wound healing appears to be unique. Since neutralizing antibodies to NGF inhibited the effects of non-adenine based purines, it appears that their ability to accelerate wound healing was mediated through NGF. Certainly, non-adenine based purines stimulate the release of both NGF and other trophic factors from several types of cells in tissue culture, including fibroblasts $[25,32]$ and astrocytes [23]. So we postulate that guanosine may also stimulate the release of NGF from cells when applied to wounds in vivo. NGF promotes wound healing in healthy mice [11-13], in genetically diabetic mice $[12,14,33]$ and in diabetic patients [42-44].

The precise mechanism by which NGF accelerates wound healing is unknown. Although it was originally assumed to be strictly a neurotrophin, it is now recognized that NGF is produced by many types of cells, including some that participate in wound healing [34], such as fibroblasts [45-47], keratinocytes [48], endothelial cells $[49,50]$ and mast cells [51]. It has also been reported recently that NGF may regulate certain immune and inflammatory responses in cells that participate in wound healing. For example, NGF promotes survival and function of immunocompetent cells, including neutrophils, eosinophils, mast cells, macrophages and lymphocytes [12, 34]. NGF, acting via its high affinity tyrosine kinase receptor A
(TrkA) [52, 53] also increases the migration of skin fibroblasts $[45,46]$ and modulates proliferation of murine [54] and human keratinocytes [55]. NGF has also been shown to promote the proliferation of endothelial cells, and increase angiogenesis, via the release of vascular endothelial growth factor (VEGF) $[49,56]$.

One important part of the action of non-adenine based purines in wound healing in relation to NGF appears to be the interaction of non-adenine based purines with NGFinducible protein kinase N. Certainly, the nucleosides inosine and guanosine are among the limited number of purine nucleosides that activate NGF-inducible protein kinase $\mathrm{N}$, a partially characterized $47-49 \mathrm{kDa}$ serinethreonine kinase [37, 38, 40]. NGF-inducible protein kinase $\mathrm{N}(\mathrm{PKN})$ is inhibited competitively by the purine analog 6-thioguanine (6-TG) with an apparent Ki of $6 \mu \mathrm{M}$. The effects of 6-TG are specific for PKN, as it has no effect on other cellular signalling molecules such as protein kinase A, protein kinase $\mathrm{C}, \mathrm{Ca}^{2+}$ calmodulin- or mitogenactivated protein kinases, or the induction of several immediate-early genes (e.g., c-fos) [37]. The purine analogue 6-MMPR [40] also inhibits NGF-inducible protein kinase $\mathrm{N}$, but it is much more potent, with an apparent $\mathrm{Ki}$ of $5 \mathrm{nM}$ [40]. Both 6-TG and 6-MMPR inhibited the ability of guanosine to promote wound healing. Together, these findings indicate that both the release of NGF from cells and the activation of the NGF-inducible protein kinase $\mathrm{N}$ may contribute to the ability of non-adenine based purines to accelerate wound healing.

One unexpected observation was the ability of guanine to promote wound healing. Bases do not interact with protein kinase $\mathrm{N}[37,38,40]$. Therefore, one must postulate a separate mechanism. One possibility is that the enzyme purine nucleoside phosphorylase converts guanine to guanosine. Another possibility is that guanine has an entirely separate, and as yet undetermined, mechanism of action. We are investigating these interesting possibilities.

The cellular responses involved in wound healing are complex, making it difficult to determine the exact cellular target of agents that promote wound healing. Nevertheless, histological examination of wounds treated with guanosine revealed several marked differences from those treated with vehicle alone and may offer some clues to potential cellular targets. It appears that guanosine may have reduced the damage to the deep subcutaneous blood vessels, thereby reducing fibrinous exudate resulting from vascular damage at the time of skin injury [4]. Guanosine also reduced inflammatory neutrophilic infiltration of the fibrinous exudate $[4,6]$. This suggests that guanosine, in some way, reduced the inflammatory response. Macrophages also play an important role early in wound healing; they are responsible for producing cytokines that influence the development of fibrinous exudate and neutrophilic infiltra- 
tion of tissues $[6,57]$. In in vitro studies, NGF has been shown to activate the phagocytosis by murine macrophages and increase the release of the inflammatory cytokine, IL- $1 \beta$ [58]. Therefore, macrophages may be important cellular targets through which guanosine and inosine accelerate wound healing.

Previously, guanosine and inosine had been shown to enhance proliferation of many cell types in cell culture, including cerebral vascular endothelial cells, microglia and astrocytes [24, 25]. Thus, one cellular mechanism by which guanosine and inosine might accelerate wound healing is by enhancing proliferation of cells involved in the process of tissue repair. Data from the present study are compatible with the hypothesis that the stimulation of proliferation of fibroblasts and macrophages may also contribute to the ability of inosine and guanosine to promote wound healing.

In diabetic animals NGF content of the peripheral nerves [59] and target organs such as skin is reduced [33], and this deficiency may contribute to the delayed repair of diabetic wounds. Topical application of NGF to the wounds of diabetic mice has been reported to accelerate wound healing $[12,14,33]$. A depletion of NGF content has also been shown in human diabetics' skin, and this was correlated with a reduced number of keratinocytes [42]. Recent studies have also demonstrated that topical application of NGF to human diabetic pressure ulcers promoted the healing of skin ulcers $[43,44]$ and improved the outcome of diabetic neuropathy [60]. As Landi et al. [44] observed an increase in wound reepithelialization in the NGF-treated diabetic ulcers, they suggested that NGF might act directly on the epithelium. In addition, NGF may also promote tissue repair by increasing angiogenesis by endothelial cells or by modulating the inflammatory response in wound healing [44].

The present study was conducted using genetically diabetic (BKS.Cg-m+/+leprdb) mice. These are clinically relevant and reproducible models of impaired wound healing $[12,14,61]$. Also like humans with adult onset diabetes (BKS.Cg-m+/+leprdb), mice have markedly delayed wound healing. They have, therefore, been used to determine the potency of several agents to overcome delayed tissue repair $[12,14,61]$. The fact that treatment with non-adenine based purines accelerated wound healing in these healing-impaired models offers the prospect of significant enhancement to the quality of life for human diabetes patients and at greatly reduced costs compared with current therapies. These findings provide additional support for the role of NGF in guanosine-induced enhancement of wound healing.

The identification of likely molecular and cellular target sites for non-adenine based purines indicates additional potential therapeutic targets that may be exploited in wound healing and in other physiological conditions that involve macrophage and fibroblast resistance.
Acknowledgements The authors thank Dr. Bruce N. Cronstein and his laboratory staff for their assistance and helpful discussions regarding the establishment of this wound-healing model in our laboratory. We also thank Dr. Michael Couglin, for the gift of NGF and anti-NGF, and Dr. Raelene Kinlough-Rathbone for critical appraisal of the manuscript. S.J. is the recipient of the Brian Keown Senior Career Investigator Award. This study was supported by grants in aid of research from Renaissance Pharmagene Inc. (M. P.R.; E.S.W.; P.B.; I.D.; S.R.; G.F.; U.T.) and M.U.R.S.T. (U.T).

\section{References}

1. Fahey TJ III, Sadaty A, Jones WG, Barber A, Smoller B, Shires GT (1991) Diabetes impairs the late inflammatory response to wound healing. J Surg Res 50:308-313

2. Currie CJ, Morgan CL, Peters JR (1998) The epidemiology and cost of inpatient care for peripheral vascular disease, infection, neuropathy, and ulceration in diabetes. Diabetes Care 21:42-48

3. Karukonda SR, Flynn TC, Boh EE, McBurney EI, Russo GG, Millikan, LE (2000) The effects of drugs on wound healing: part 1. Int J Dermatol 39:250-257

4. Martin P (1997) Wound healing-aiming for perfect skin regeneration. Science 276:75-81

5. Pierce GF, Mustoe TA (1995) Pharmacologic enhancement of wound healing. Annu Rev Med 46:467-481

6. Gillitzer R, Goebeler M (2001) Chemokines in cutaneous wound healing. J Leukoc Biol 69:513-521

7. Werner S, Grose R (2003) Regulation of wound healing by growth factors and cytokines. Physiol Rev 83:835-870

8. Fu X, Li X, Cheng B, Chen W, Sheng Z (2005) Engineered growth factors and cutaneous wound healing: success and possible questions in the past 10 years. Wound Repair Regen 13:122-130

9. Lewin GR, Barde YA (1996) Physiology of the neurotrophins. Annu Rev Neurosci 19:289-317

10. Sofroniew MV, Howe CL, Mobley WC (2001) Nerve growth factor signaling, neuroprotection, and neural repair. Annu Rev Neurosci 24:1217-1281

11. Li AK, Koroly MJ, Schattenkerk ME, Malt RA, Young M (1980) Nerve growth factor: acceleration of the rate of wound healing in mice. Proc Natl Acad Sci US A 77:4379-4381

12. Matsuda H, Koyama H, Sato H, Sawada J, Itakura A, Tanaka A, Matsumoto M, Konno K, Ushio H, Matsuda K (1998) Role of nerve growth factor in cutaneous wound healing: accelerating effects in normal and healing-impaired diabetic mice. J Exp Med 187:297-306

13. Nithya M, Suguna L, Rose C (2003) The effect of nerve growth factor on the early responses during the process of wound healing. Biochim Biophys Acta 1620:25-31

14. Muangman P, Muffley LA, Anthony JP, Spenny ML, Underwood RA, Olerud JE, Gibran NS (2004) Nerve growth factor accelerates wound healing in diabetic mice. Wound Repair Regen 12:44-52

15. Montesinos MC, Gadangi P, Longaker M, Sung J, Levine J, Nilsen D, Reibman J, Li M, Jiang CK, Hirschhorn R, Recht PA, Ostad E, Levin RI, Cronstein BN (1997) Wound healing is accelerated by agonists of adenosine A2 (G alpha s-linked) receptors. J Exp Med 186:1615-1620

16. Fredholm BB, IJzerman AP, Jacobson KA, Klotz KN, Linden J (2001) International Union of Pharmacology. XXV. Nomenclature and classification of adenosine receptors. Pharmacol Rev 53:527-552

17. Victor-Vega C, Desai A, Montesinos MC, Cronstein BN (2002) Adenosine $\mathrm{A}_{2 \mathrm{~A}}$ receptor agonists promote more rapid wound healing than recombinant human platelet-derived growth factor (Becaplermin gel). Inflammation 26:19-24 
18. Sun LL, Xu LL, Nielsen TB, Rhee P, Burris D (1999) Cyclopentyladenosine improves cell proliferation, wound healing, and hair growth. J Surg Res 87:14-24

19. Wang DJ, Huang NN, Heppel LA (1990) Extracellular ATP shows synergistic enhancement of DNA synthesis when combined with agents that are active in wound healing or as neurotransmitters. Biochem Biophys Res Commun 166:251-258

20. Abbracchio MP, Burnstock G (1998) Purinergic signalling: pathophysiological roles. Jpn J Pharmacol 78:113-145

21. Greig AV, James SE, McGrouther DA, Terenghi G, Burnstock G (2003) Purinergic receptor expression in the regeneration epidermis in a rat model of normal and delayed wound healing. Exp Dermatol 12:860-871

22. Greig AV, Linge C, Terenghi G, McGrouther DA, Burnstock G (2003) Purinergic receptors are part of a functional signaling system for proliferation and differentiation of human epidermal keratinocytes. J Invest Dermatol 120:1007-1015

23. Di Iorio P, Caciagli F, Giuliani P, Ballerini P, Ciccarelli R, Sperling O, Zoref-Shani E, Benowitz L, Traversa U, Bombi G, Florio T, Virgilio A, Andrew CM, Crocker CE, Werstiuk ES, Middlemiss PJ, Rathbone MP (2001) Purine nucleosides protect injured neurons and stimulate neuronal regeneration by intracellular and membrane receptor-mediated mechanisms. Drug Dev Res 52:303-315

24. Rathbone MP, Middlemiss PJ, Gysbers JW, DeForge S, Costello P, Del Maestro RF (1992) Purine nucleosides and nucleotides stimulate proliferation of a wide range of cell types. In Vitro Cell Dev Biol 28A:529-536

25. Rathbone MP, Middlemiss PJ, Gysbers JW, Andrew C, Herman MA, Reed JK, Ciccarelli R, Di Iorio P, Caciagli F (1999) Trophic effects of purines in neurons and glial cells. Prog Neurobiol 59:663-690

26. Traversa U, Bombi G, Di Iorio P, Ciccarelli R, Werstiuk ES, Rathbone MP (2002) Specific [(3)H]-guanosine binding sites in rat brain membranes. Br J Pharmacol 135:969-976

27. Gysbers JW, Rathbone MP (1992) Guanosine enhances NGF-stimulated neurite outgrowth in PC12 cells. Neuroreport 3:997-1000

28. Gysbers JW, Rathbone MP (1996) Neurite outgrowth in PC12 cells is enhanced by guanosine through both cAMP-dependent and -independent mechanisms. Neurosci Lett 220:175-178

29. Gysbers JW, Rathbone MP (1996) GTP and guanosine synergistically enhance NGF-induced neurite outgrowth from PC12 cells. Int J Dev Neurosci 14:19-34

30. Neary JT, Rathbone MP, Cattabeni F, Abbracchio MP, Burnstock G (1996) Trophic actions of extracellular nucleotides and nucleosides on glial and neuronal cells. Trends Neurosci 19:13-18

31. Traversa U, Di Iorio P, Palmieri C, Bombi G, Ciccarelli R, Caciagli F (2002) Identification of a guanosine receptor linked to the modulation of adenylate cyclase and MAPK activity in primary cultures of rat astrocytes. Italian Purine Club Meeting 9

32. Middlemiss PJ, Gysbers JW, Rathbone MP (1995) Extracellular guanosine and guanosine- $5^{\prime}$-triphosphate increase NGF synthesis and release from cultured mouse neopallial astrocytes. Brain Res 677:152-156

33. Graiani G, Emanueli C, Desortes E, Van Linthout S, Pinna A, Figueroa CD, Manni L, Madeddu P (2004) Nerve growth factor promotes reparative angiogenesis and inhibits endothelial apoptosis in cutaneous wounds of type 1 diabetic mice. Diabetologia 47:1047-1054

34. Kawamoto K, Matsuda H (2004) Nerve growth factor and wound healing. Prog Brain Res 146:369-384

35. Glasky AJ, Kirat S, Middlemiss PJ, Gysbers JW, Rathbone MP (1995) A novel purine derivative AIT- 082 increases synthesis of NGF, FGF-2 and NT-3 mRNA in astrocytes. Society for Neuroscience 21:751

36. Greene LA, Volonte C, Chalazonitis A (1990) Purine analogs inhibit nerve growth factor promoted neurite outgrowth by sympathetic and sensory neurons. J Neurosci 10:1479-1485
37. Volonte C, Rukenstein A, Loeb DM, Greene LA (1989) Differential inhibition of nerve growth factor responses by purine analogues: correlation with inhibition of a nerve growth factoractivated protein kinase. J Cell Biol 109:2395-2403

38. Volonte C, Greene LA (1992) Nerve growth factor-activated protein kinase $\mathrm{N}$. Characterization and rapid near homogeneity purification by nucleotide affinity-exchange chromatography. J Biol Chem 267:21663-21670

39. Benowitz LI, Jing Y, Tabibiazar R, Jo SA, Petrausch B, Stuermer CA, Rosenberg PA, Irwin N (1998) Axon outgrowth is regulated by an intracellular purine-sensitive mechanism in retinal ganglion cells. J Biol Chem 273:29626-29634

40. Volonte C, Greene LA (1992) 6-Methylmercaptopurine riboside is a potent and selective inhibitor of nerve growth factor-activated protein kinase N. J Neurochem 58:700-708

41. Hellweg R, Hartung HD (1990) Endogenous levels of nerve growth factor (NGF) are altered in experimental diabetes mellitus: a possible role for NGF in the pathogenesis of diabetic neuropathy. J Neurosci Res 26:258-267

42. Anand P, Terenghi G, Warner G, Kopelman P, Williams-Chestnut RE, Sinicropi DV (1996) The role of endogenous nerve growth factor in human diabetic neuropathy. Nat Med 2:703-707

43. Bernabei R, Landi F, Bonini S, Onder G, Lambiase A, Pola R, Aloe L (1999) Effect of topical application of nerve-growth factor on pressure ulcers. Lancet 354:307

44. Landi F, Aloe L, Russo A, Cesari M, Onder G, Bonini S, Carbonin PU, Bernabei R (2003) Topical treatment of pressure ulcers with nerve growth factor: a randomized clinical trial. Ann Intern Med 139:635-641

45. Kohyama T, Liu X, Wen FQ, Kobayashi T, Abe S, Ertl R, Rennard SI (2002) Nerve growth factor stimulates fibronectininduced fibroblast migration. J Lab Clin Med 140:329-335

46. Micera A, Vigneti E, Pickholtz D, Reich R, Pappo O, Bonini S, Maquart FX, Aloe L, Levi-Schaffer F (2001) Nerve growth factor displays stimulatory effects on human skin and lung fibroblasts, demonstrating a direct role for this factor in tissue repair. Proc Natl Acad Sci USA 98:6162-6167

47. Oger J, Arnason BG, Pantazis N, Lehrich J, Young M (1974) Synthesis of nerve growth factor by L and $3 \mathrm{~T} 3$ cells in culture. Proc Natl Acad Sci USA 71:1554-1558

48. Tron VA, Coughlin MD, Jang DE, Stanisz J, Sauder DN (1990) Expression and modulation of nerve growth factor in murine keratinocytes (PAM 212). J Clin Invest 85:1085-1089

49. Cantarella G, Lempereur L, Presta M, Ribatti D, Lombardo G, Lazarovici P, Zappala G, Pafumi C, Bernardini R (2002) Nerve growth factor-endothelial cell interaction leads to angiogenesis in vitro and in vivo. FASEB J 16:1307-1309

50. Gibran NS, Tamura R, Tsou R, Isik FF (2003) Human dermal microvascular endothelial cells produce nerve growth factor: implications for wound repair. Shock 19:127-130

51. Leon A, Buriani A, Dal Toso R, Fabris M, Romanello S, Aloe L, Levi-Montalcini R (1994) Mast cells synthesize, store, and release nerve growth factor. Proc Natl Acad Sci USA 91: 3739-3743

52. Huang EJ, Reichardt LF (2003) Trk receptors: roles in neuronal signal transduction. Annu Rev Biochem 72:609-642

53. Kaplan DR, Miller FD (2000) Neurotrophin signal transduction in the nervous system. Curr Opin Neurobiol 10:381-391

54. Paus R, Luftl M, Czarnetzki BM (1994) Nerve growth factor modulates keratinocyte proliferation in murine skin organ culture. Br J Dermatol 130:174-180

55. Di Marco E, Mathor M, Bondanza S, Cutuli N, Marchisio PC, Cancedda R, De Luca M (1993) Nerve growth factor binds to normal human keratinocytes through high and low affinity receptors and stimulates their growth by a novel autocrine loop. J Biol Chem 268:22838-22846 
56. Emanueli C, Salis MB, Pinna A, Graiani G, Manni L, Madeddu P (2002) Nerve growth factor promotes angiogenesis and arteriogenesis in ischemic hindlimbs. Circulation 106:2257-2262

57. DiPietro LA (1995) Wound healing: the role of the macrophage and other immune cells. Shock 4:233-240

58. Susaki Y, Shimizu S, Katakura K, Watanabe N, Kawamoto K, Matsumoto M, Tsudzuki M, Furusaka T, Kitamura Y, Matsuda H (1996) Functional properties of murine macrophages promoted by nerve growth factor. Blood 88:4630 - 4637
59. Hellweg R, Wohrle M, Hartung HD, Stracke H, Hock C, Federlin K (1991) Diabetes mellitus-associated decrease in nerve growth factor levels is reversed by allogeneic pancreatic islet transplantation. Neurosci Lett 125:1-4

60. Pittenger G, Vinik A (2003) Nerve growth factor and diabetic neuropathy. Exp Diabesity Res 4:271-285

61. Greenhalgh DG, Sprugel KH, Murray MJ, Ross R (1990) PDGF and FGF stimulate wound healing in the genetically diabetic mouse. Am J Pathol 136:1235-1246 